\title{
Referral and survival of patients accepted by terminal care support team
}

\author{
CHRISTOPHER EVANS AND MARK MCCARTHY \\ From the Department of Community Medicine, University College, University Street, London WC1E 6JJ
}

SUMMARY The first year's work of Bloomsbury terminal care support team has been analysed from routinely recorded information. The patients accepted by the team were of younger average age than all people dying from cancer within the catchment population. The median survival of patients after first contact with the team was 49 days, but survival of patients referred by general practitioners and hospital general physicians was substantially shorter than of those referred by hospital oncologists and radiotherapists. The growing number of district terminal care services suggests the need for continued research to develop guidelines for referral of patients and methods of evaluating the team's work.

The philosophical and ethical issues of caring for dying people have been widely described, but less attention has been given to health services research on terminal care. Retrospective studies in Britain ${ }^{1-4}$ have described the quality of life of people before death as recounted by their relatives and carers. Many of the patients have endured substantial suffering when treated both in hospital and at home. Hinton $^{5}$ interviewed selected groups of patients receiving terminal care in a hospital, a home, and a hospice. The patients were least depressed and anxious at the hospice and preferred the frank communication there.

Kane et $a l^{6}$ have reported a prospective, randomised controlled trial between hospice and conventional care at a Veterans' Administration hospital in California, USA. The two groups did not differ in symptom control, activities of daily living or psychological state, but there was more satisfaction with the hospice. The authors caution that their findings may not be widely applicable, because the organisational arrangements for care will be different elsewhere. Only a selected group of the United States population are eligible for Veterans' Administration services, and the patients are almost all men. Only 5\% of these patients died at home compared with $30 \%$ who die at home in Britain.

In all these studies the alternative to conventional care has been a hospice. We have sought to evaluate the work of a terminal care support team. A support team assists relatives and caregivers of patients with cancer who are at home, including those who wish to die there, and also sees patients in hospital outpatients and wards. The team uses the concepts developed in hospice care, seeking to educate the hospital and community services about good terminal care and also to improve the patient's and family's understanding of dying.

Specialist terminal care services have increased rapidly in Britain during the last 10 years. Although the first services were developed in hospices, a survey in December $1980^{7}$ found that there were 32 home care support teams in Great Britain, whereas in 1975 there had been only two. The survey also asked about new services planned to start in 1981; of the 17 new services planned, 14 were home care teams. Discussing their findings, the authors recommended that further developments should increase the provision of home and hospital support rather than hospice beds, primarily for financial reasons.

In 1981, South Camden Health District set up a multidisciplinary terminal care support team, partly modelled on that operating from St Thomas's Hospital. $^{8}$ The team works both within the hospital and in the community but has no designated inpatient beds. It consists of two full-time nurses, a full-time social worker, and a part-time doctor. A consultant radiotherapist is also a member of the team and takes overall responsibility for it; a team nurse or doctor is available on call at all times, but clinical responsibility for individual patients remains with their own doctor.

Referrals are accepted from all hospital consultants and general practitioners for patients living within the health authority boundaries. South Camden Health District was replaced on 1 April 1982 by Bloomsbury District Health Authority, 10 
which includes South Camden and North Westminster. However, the team received no referrals from the new part of the catchment area during the period of study.

We give here some of the descriptive information that can be recorded routinely by a terminal care support team. Information on survival and referral raises questions about the most effective working of the team.

\section{Methods}

During the first months of operation of the team (late May to October 1982) a standardised record system for clinical research information was developed. Demographic information about the patients recorded, and information on survival was abstracted from the clinical records up to January 1984 . For comparison, population data were available from the 1981 census and the record of deaths in Bloomsbury district for 1982 from the Office of Population Censuses and Surveys (form SD25).

Actuarial survival curves were calculated using Biomedical Data Programs, ${ }^{9}$ and comparisons of survival were made using Breslow's generalised Wilcoxon statistic. ${ }^{10}$ This test weights early differences in survival higher than later differences: the log-rank test often used for such comparisons weights later differences more heavily than earlier ones. All statistical tests are two-tailed. Peto et al ${ }^{\mathbf{1 1}}$ encourage retrospective analysis as a valuable part of a study of survival, although the power of the statistical tests is limited by the numbers in the smallest group. We have calculated the power of Breslow's statistic according to the method of Makuch and Simon. ${ }^{12}$

\section{Results}

One hundred and forty-one patients were referred between May 1982 and the beginning of June 1983. Sixteen patients were seen but not accepted for continuing care during this period because they lived outside the district or for other reasons. The team saw 125 patients living within South Camden, a referral rate of 206 patients per 100000 population per year. There were an estimated 228 cancer deaths in South Camden and 437 in the whole Bloomsbury district in 1982. Thus just over half (55\%) of all people dying of cancer in South Camden were referred to the team and just over a quarter (29\%) of cancer deaths in the whole district.

\section{DES CRIPTION}

There were 64 men and 61 women, with mean ages 65.3 and 63.9 respectively and an overall mean age of $64 \cdot 6$. (The age of one man was not recorded.) The age distributions did not differ significantly (see table 1). However, in comparison with all cancer deaths in Bloomsbury district in 1982 , more young patients were referred to the team than expected, and fewer old people.

Table 1 Patients by age group and sex, and comparison with all cancer deaths in the district

\begin{tabular}{lccccc}
\hline & \multicolumn{2}{l}{ Patients referred } & & Bloomsbury \\
\cline { 2 - 5 } Age group & Men & Women & Total & $\begin{array}{l}\text { O/E } \\
\text { ratio }\end{array}$ \\
\hline $0-44$ & 4 & 5 & 9 & 12 & $2 \cdot 67$ \\
$45-54$ & 7 & 11 & 18 & 27 & $2 \cdot 38$ \\
$55-64$ & 17 & 12 & 29 & 94 & $1 \cdot 10$ \\
$65-74$ & 23 & 18 & 41 & 143 & 1.02 \\
$75-84$ & 9 & 14 & 23 & 119 & 0.69 \\
$85+$ & 3 & 1 & 4 & 42 & 0.34 \\
Total & $63^{*}$ & 61 & $124^{*}$ & 437 & 1.00 \\
\hline
\end{tabular}

*Age of one patient unrecorded.

Comparison with all cancer deaths: $\chi^{2}=73 \cdot 37$, df $=5, p<0 \cdot 001$.

All the patients referred to the team had cancer. The distribution of the referrals by diagnostic group is shown in table 2 and compared with the deaths from cancer in Bloomsbury for 1982. Relatively fewer patients were referred with gastrointestinal, breast, and haematologic cancers than expected, and relatively more with oropharyngeal and lung cancers.

The address of the next-of-kin was recorded in the notes for all but four of the patients. In 74 of these the next-of-kin lived at the same address as the patient. Wives were the recorded next-of-kin more than twice as often as husbands, and daughters and sons were each recorded as frequently as husbands.

Table 2 Patients by diagnostic group, and comparison with all cancer deaths in the district

\begin{tabular}{lccc}
\hline Diagnostic group & $\begin{array}{c}\text { Patients } \\
\text { referred }\end{array}$ & $\begin{array}{l}\text { Bloomsbury } \\
\text { District }\end{array}$ & $\begin{array}{l}\text { O/E } \\
\text { ratio }\end{array}$ \\
\hline F 08 lip, mouth, pharynx & 5 & 4 & 4.46 \\
F 09 gastrointestinal & 22 & 117 & 0.67 \\
F 10 intrathoracic & 49 & 128 & 1.36 \\
F 11 breast, bone, skin & 8 & 46 & 0.62 \\
F 12 genitourinary & 26 & 73 & 1.27 \\
F 13 other and unspecified & 10 & 41 & 0.87 \\
F 14 lymph haemopoietic & 5 & 28 & 0.64 \\
& & & \\
All diagnoses & 125 & 437 & 1.00 \\
\hline
\end{tabular}

SURVIVAL

The median survival of patients after first contact with the team was 49 days. We expected that a number of patients very close to death would be referred in the first few months of the team's 
operation, and that a pattern of earlier referral would become established thereafter. However, when we compared those patients referred in the first two months, we found the opposite results. Median survival of the early group $(n=35)$ was 70 days, and of the later group $(n=90) 45$ days. The difference in actuarial survival is not significant (Breslow's statistic $=2.78, \quad$ df $=1, \quad p=0.095 ;$ but $<80 \%$ confidence to detect a $100 \%$ difference in survival at $\mathrm{p}<0.05$ ).

Women patients lived longer than the men. Their median survivals were 54 days and 44 days respectively (not significant: Breslow's statistic $=2 \cdot 14, \mathrm{df}=1, \mathrm{p}=0 \cdot 14 ; 95 \%$ confidence to detect a $100 \%$ difference in survival at $\mathrm{p}<0.05$ ). A scattergram of survival against age revealed no relation nor any obvious groupings.

Primary cancers of the respiratory and intrathoracic organs were the commonest referrals to the team, accounting for $39 \%$, and also had the highest $\mathrm{O} / \mathrm{E}$ ratio apart from cancers of the lip, oral cavity, and pharynx. The intrathoracic cancers had a significantly shorter median survival (38 days) compared with the rest (69 days: Breslow's statistic $=5 \cdot 20, \mathrm{df}=1, \mathrm{p}=0 \cdot 015)$. The numbers of deaths for other diagnoses are too small to provide useful analyses.

To reflect the presence or absence of social support we separated the referrals into two groups: those with next-of-kin living at the same address, and those with no known next-of-kin or those with next-of-kin living elsewhere. Seventy-four patients in the "supported" category had a median survival of $\mathbf{4 0}$ days, whereas 47 patients who were "unsupported" had a median survival of 73 days; insufficient details were available for classification of four referrals. Although the difference fails to reach conventional significance (Breslow's statistic $=3 \cdot 36, \mathrm{df}=1, \mathrm{p}=0.067 ; 90 \%$ confidence to detect a $100 \%$ difference at $p=0.05$ ), it might be expected that earlier referral would occur when patients are living apart from their relatives.

\section{REFERRA L}

We divided referrals to the team into four groups: from general practitioners $(n=20)$, from general hospital consultants $(n=45)$, from oncologists $(n=18)$, and from radiotherapists $(n=42)$. Table 3 shows the pattern of referral over time. There was a large number of patients in the starting-up period, which fell and then began to increase again. Radiotherapy referrals were greatest at the start, probably reflecting the management relationship of the team. A relatively small proportion of referrals was from general practitioners.

There were no significant differences in mean age between the referral groups, but the proportion of
Table 3 Number of patients referred, by month and source

\begin{tabular}{lrrrrrrr}
\hline Source & $\begin{array}{l}\text { Junel } \\
\text { July }\end{array}$ & $\begin{array}{l}\text { Augl } \\
\text { Sep }\end{array}$ & $\begin{array}{l}\text { Oct/ } \\
\text { Nov }\end{array}$ & $\begin{array}{l}\text { Decl } \\
\text { Jan }\end{array}$ & $\begin{array}{l}\text { Feb/ } \\
\text { Mar }\end{array}$ & $\begin{array}{l}\text { Apr/ } \\
\text { May }\end{array}$ & Total \\
\hline Radiotherapist & 19 & 7 & 5 & 3 & 4 & 4 & 42 \\
Oncologist & 4 & 1 & 3 & 1 & 3 & 6 & 18 \\
General consultant & 8 & 5 & 7 & 6 & 10 & 9 & 45 \\
General practitioner & 6 & 1 & 3 & 3 & 3 & 4 & 20 \\
Total & 37 & 14 & 18 & 13 & 20 & 23 & 125 \\
\hline
\end{tabular}

male patients increased from $29 \%$ for referrals from oncologists to $40 \%$ for general practitioners, $51 \%$ for radiotherapists, and $64 \%$ for general hospital consultants. This difference is just non-significant $\left(\chi^{2}=7 \cdot 39, \mathrm{df}=1, \mathrm{p}=0.06\right)$ but may represent a true difference in treatment interests between physicians. Radiotherapists and oncologists also referred more patients with intrathoracic primaries, $71 \%$ and $70 \%$ repectively compared with $50 \%$ and $56 \%$ for GPs and general hospital consultants respectively, but this difference did not reach statistical significance $\left(\chi^{2}=3.63, \mathrm{df}=3, \mathrm{p}=0.31\right)$.

REFERRAL AND SURVIVAL TOGETHER

Cumulative survival curves for the four referral sources are shown in the figure. Patients referred by the general hospital consultants and generald practitioners had substantially shorter survival than those referred by oncologists and radiotherapists (Breslow's statistic $=29.25, \mathrm{df}=3, \mathrm{p}<0.0001$ ) The median survival for patients referred by radiotherapists was 104 days. One in three of the patients referred by oncologists and radiotherapists lived for more than four months.

\section{Discussion}

The characteristics of a population-based group of patients referred to a terminal care support team have not been reported previously. Compared with

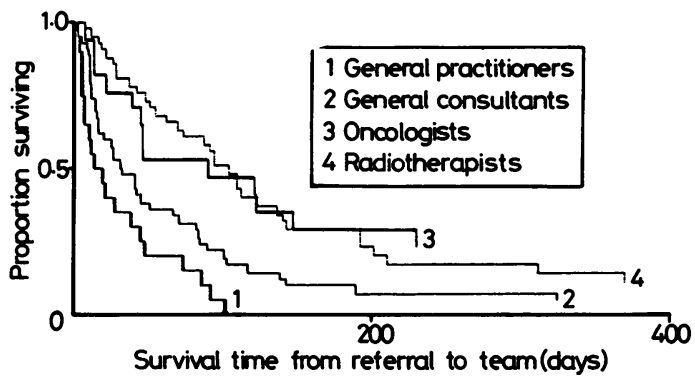

Survival of patients referred to terminal care support team by different clinician groups. 
all patients dying of cancer in the district, they tended to be younger, although they had a similar average age to patients accepted for the randomised controlled trial between hospice and conventional care in California. ${ }^{6}$ Again compared with all district cancer deaths, there were relatively more patients than expected with lung cancer and fewer with cancer of the breast and gastrointestinal organs. We have no reason to believe that the symptoms or needs of patients with terminal cancer would vary according to the primary organ affected and suggest that these differences reflect the patterns of referral.

The length of time between a patient's first contact with the team and death was calculated. A terminal care team would be expected to have referred to it patients with a short survival, and the median for the study group was 49 days. In contrast, the Veterans' Administration study ${ }^{6}$ and Parkes' survey ${ }^{3}$ of cancer deaths in patients under 65 with living spouses both reported a median survival of between 60 and 70 days. However, this difference may be explained because the VA study design used an estimated prognosis of two weeks to six months as a criterion of entry, and Parkes was describing the period after active treatment had been completed. Nevertheless the median period for our study varied substantially according to the pattern of referral. The patients referred by general practitioners had a median survival of 18 days, compared with 104 days for radiotherapy referrals.

These survival patterns suggest that different groups of doctors have different perceptions of the purpose of a terminal care support team. Studies of dying in the general population show that many patients and their relatives still have substantial symptoms such as pain and anxiety that are not relieved by current services. Wilkes describes a vivid example of unsatisfactory care: "One relative threw a face flannel at a general practitioner shouting 'You call this dying with dignity!'” Less than half of all patients dying with cancer in Bloomsbury district were referred to the terminal care support team during their first year of work. Although many of these patients were under the care of doctors recognising the value of terminal care support, ${ }^{13}$ other referring doctors may have had little interest in terminal care.

The value of specialised terminal care services has yet to be established. Parkes ${ }^{3}$ and Hinton ${ }^{5}$ both showed greater symptom control and satisfaction in patients cared for in hospices than elsewhere, but the studies were retrospective and the patients were not randomly allocated. In the Veterans' Administration study, the patients were more satisfied with hospice than with conventional care, but there were no differences in pain control or mood, and neither service achieved a statistically significant treatment effect for either depression or anxiety.

However, a terminal care support service is seeking to help with a wider range of problems than these. Wilkes described the important anxieties of relatives and patients at home as "the difficulties in getting medical help at night, except through a deputising doctor who knew nothing of the case, and in getting any trusted, familiar out-of-hours advice, and delays of up to 4 or even 8 weeks in obtaining basic equipment such as incontinence pads or commodes." The defined objectives of the team should be included in the criteria for evaluation of their service.

When is the best time for a clinician to refer a patient to a terminal care team? Health care staff overestimate their patients' survival, ${ }^{14}{ }^{15}$ and a referral planned for when active treatment is finished may be too late: Parkes ${ }^{3}$ found that $18 \%$ of his study group died while still being treated. Too short a time between referral and death may not allow the emotional relationship needed for open communication between the patient, the family, and the team to be established. On the other hand, the long survival of some of the patients in our study, and also in Parkes' study, indicate that a better assessment of likely prognosis is needed.

We question the view of Lunt and Hillier ${ }^{7}$ that terminal care teams for home care and hospital support are likely to prove more cost-effective than those for hospices. Referral to a terminal care team may lead to more hospitalisation rather than home care. We see the value of a support team as improving the quality of dying, for the patient and the relatives, rather than changing the balance between home and institutional care.

Many operational questions about terminal care services remain unanswered. What is the optimum proportion of patients that should be referred, and at what stage? Who should make the referral? How many visits are needed per patient, and what level of staffing is appropriate? Some of these issues could be resolved if more information was recorded regularly by terminal care teams. This might include the date of diagnosis, the date at stopping active treatment, and estimates of the patient's quality of life and prognosis at the time of referral. Other districts should be encouraged to review their routine statistics for comparison. As terminal care is one of the most rapidly expanding services of health care, there should be an interest in continuing health services research in the field.

We thank Dr Jeffery Tobias, consultant radiotherapist, and Alison Grey, Jill Highat, Julia Franklin, Dr Rosie McConnell, and Dr Claudia 
Grainger-Taylor, members of the Bloomsbury terminal care support team, for their interest and participation in the study. Dr John Fuller and Professor Roy Acheson gave helpful comments on an earlier version of this paper.

Correspondence should be addressed to $\mathrm{Dr}$ Christopher Evans, Springfield Hospital, London SW17.

\section{References}

${ }^{1}$ Cartwright A, Hockey L, Anderson JL. Life before death. London: Routledge \& Kegan Paul, 1973.

${ }^{2}$ Ward AWM. Terminal care in malignant disease. Soc Sci Med 1974; 8: 413-20.

${ }^{3}$ Parkes CM. Home or hospital? Terminal care as seen by surviving spouses. J R Coll Gen Pract 1978; 28: 19-30.

${ }^{4}$ Wilkes E. Dying now. Lancet 1984; i: 950-2.

${ }^{5}$ Hinton J. Comparison of places and policies for terminal care. Lancet 1979; i: 29-32.
${ }^{6}$ Kane RL, Wales J, Bernstein L, Leibowitz A, Kaplan S. A randomised controlled trial of hospice care. Lancet 1984 ; i: $890-4$.

${ }^{7}$ Lunt B, Hillier R. Terminal care: present services and future priorities. $\mathrm{Br}$ Med $J$ 1981; 283: 595-8.

${ }^{8}$ Bates T, Hoy AM, Clarke DG, Laird PP. The St. Thomas's Hospital terminal care support team. Lancet 1981; i: 1201-3.

${ }^{9}$ Benedetti J, Yuen K, Young L. In: Biomedical data programs: statistical software. Dixon WJ, Brown MB, Engleman L, eds. Berkeley, California 1981: 557-74.

${ }^{10}$ Breslow N. A generalised Kruskal-Wallis test for comparing $\kappa$ samples subject to unequal patterns of censorship. Biometrika 1970; 57: 579-94.

${ }^{11}$ Peto R, Pike MC, Armitage P, et al. Design and analysis of randomised clinical trials requiring prolonged observation of each patient. 1. Introduction and design. Br J Cancer 1976; 34: 585-612.

${ }^{12}$ Makuch RW, Simon RM. Sample size requirements for comparing time-to-failure among $\kappa$ treatment groups. $J$ Chron Dis 1982; 35: 861-7.

${ }^{13}$ Souhami RL. Teaching what to say about cancer. Lancet 1978; ii: 935-6.

${ }^{14}$ Parkes CM. Accuracy of predictions of survival in later stages of cancer. Br Med J 1972; 2: 29-31.

${ }^{15}$ Evans C, McCarthy M. Prognostic accuracy by a terminal care support team. In preparation. 